\title{
Lower Ribs Pain
}

National Cancer Institute

\section{Source}

National Cancer Institute. Lower Ribs Pain. NCI Thesaurus. Code C35636.

A sensation of discomfort emanating from the inferiormost (verterbrochondral or vertebral) ribs. 